\title{
Student Teachers' Physics Knowledge and Sources of Knowledge to Explain Everyday Phenomena
}

\author{
Nilüfer Didiş Körhasan' ${ }^{1}$, Derya Kaltakçı Gürel ${ }^{2 *}$ \\ ${ }^{1}$ Department of Mathematics and Science Education, Faculty of Education, Zonguldak Bülent Ecevit University, Zonguldak, Turkey, ${ }^{2}$ Department of \\ Mathematics and Science Education, Faculty of Education, Kocaeli University, Kocaeli, Turkey
}

*Corresponding Author: deryakaltakci@gmail.com

\section{ABSTRACT}

Experience and intuition may help explain everyday phenomena. However, physics concepts cannot be induced directly from them. Learning physics requires an examination of the ideas of scientifically constructed theoretical frameworks, explaining coherently organized physics concepts. This research examined student teachers' physics knowledge in terms of their everyday explanations and physical reasoning pertaining to everyday concepts. The way in which sources of knowledge influence student teachers' physics learning was also examined. With this aim, a test comprising eight questions - with each question corresponding to an everyday context examining students' everyday explanations, their reasoning, and epistemologies - were developed. By convenience sampling of two universities in Turkey, the test was offered to 360 student teachers who will teach primary and elementary level science in the future. After the relevant t-tests and variance analyses, the results indicated that there was context-sensitivity with respect to physical explanations. In addition, in all of the contexts, propagated and fabricated knowledge allowed the highest scores in each context despite the different kinds of sources stated by student teachers. Educators should have insights about the nature of students' knowledge and reasoning, and they should design their science-related courses by considering students' epistemologies to remove the hidden barrier between every day and formal concepts.

KEY WORDS: physics education; epistemology; everyday conceptions

\section{INTRODUCTION}

\section{Learning Physics}

$\mathbf{P}$ hysics education research examines students' problems in understanding physics and other issues such as teachers, textbooks, and curricula which are tightly connected with learning physics. It also develops pedagogical methods and techniques to overcome students' difficulties and misconceptions for better physics learning. A significant amount of research on students' understanding of physics concepts over the past 30 years has revealed students' difficulties in learning physics and reflected their poorly organized physics knowledge, as well as their misconceptions in different physics concepts such as force and motion (Beichner, 1994; Hestenes et al. 1992; Hestenes \& Wells, 1992; Thornton \& Sokoloff, 1998), electricity (Engelhardt \& Beichener, 2004; Peşman \& Eryılmaz, 2010), heat and temperature (Lewis \& Linn, 1994), optics (Kaltakci-Gurel et al., 2017) and even quantum theory (Didiş et al., 2014; Ivanjek et al., 2015; Vokos et al., 2000), and other relatively difficult to grasp physical phenomena (Chi et al., 1981; Hammer, 1994; Itza-Ortiz et al., 2004; Reif, 1995; Wittmann et al., 1999).

While some student difficulties are based on mathematical skills and attitudes toward physics learning, some research has indicated that students might have well-established intuitive belief systems influencing their physics learning (Halloun and
Hestenes, 1985a \& 1985b; Hestenes et al., 1992). However, learning physics involves more than simply finding ideas from prior knowledge and experience. It also requires an examination of ideas embracing a theoretical framework (Hammer \& Elby, 2003) because physics knowledge includes scientifically constructed theoretical frameworks for explaining coherently organized concepts. Modification of common sense with what is learned in physics classes (Hammer, 1994) and coherently organizing physics knowledge is required for students' physics learning (Reif, 1995, 1997). However, students sometimes have difficulty in deciding which ideas should be modified and which of them are to be maintained when learning physics (Hammer and Elby, 2003). At that point, epistemology, which corresponds to students' ideas about knowledge and learning, has a role with respect to learning physics.

\section{Student Epistemology and Physics Knowledge}

Individual's ideas about knowledge and learning are described as "epistemology" (Hammer \& Elby, 2003). Epistemological beliefs have causal effects on physics learning (Ding, 2014) because students' epistemologies could directly influence their learning of physics by effecting their approach to learning materials (Ding, 2014; Hammer, 1994; Hammer \& Elby, 2003; Lising \& Elby, 2005). Their epistemological beliefs also help them to drive metacognitive strategies when they are learning physics (Hammer \& Elby, 2003; Lising \& Elby, 2005). 
Many of the students' difficulties in physics are explained by their epistemological nature (Lising \& Elby, 2005); that is, the epistemic failure in making connections between everyday thinking and formal thinking in physics (Ding, 2014). Considering Einstein's statement about science being a refinement of everyday thinking (Hammer \& Elby, 2003), everyday life is composed of physical contexts that could be explained scientifically. In daily life, most people, independent of their science background and age, engage with these scientific situations and they present their "own" methodologies to handle the everyday problem emerging from the context such as developing an idea, becoming more familiar with another person or experiencing the context. Approaching the problem may differ due to their epistemologies. For example, students who have difficulty in physics may consider that physics is a collection of facts and formulas, is independent of everyday thinking, and memorizing the material is required to learn physics. In contrast, successful physics learners see physics as a coherent system of ideas; its formalism is a way of expressing ideas, and reconstruction and refinement of understanding are required to learn physics (Hammer \& Elby, 2003).

Songer and Linn's (1991) study suggested that students' dynamic, interpretive, and experience-integrated knowledge allowed students to obtain significantly higher scores than students with static, factual knowledge and who were isolated from everyday life. Lising and Elby (2005) examined a physics student's epistemology using a case study and found evidence of an epistemological barrier between formal and everyday reasoning. Because of its disconnected nature, this barrier limited the student's searching for connections and her use of formal reasoning for answering the questions. However, the authors also found that the student presented more reconciliation within everyday reasoning or within formal reasoning. Hammer designed an elective course named "How to learn physics-HTLP" (Hammer \& Elby, 2003. p. 61) with a seminar style, focusing on epistemological topics and aiming to help students' understanding and approaching physics learning as a "refinement of everyday thinking" (Hammer and Elby, 2003. p. 62) by developing awareness of everyday thinking and developing a relevant framework (Hammer \& Elby, 2003). Elby's design in 1998 aimed to help students develop productive resources. In contrast to textbooks presenting fully formal definitions and equations, he taught students that "learning physics often involves starting with everyday knowledge and experience, and building from there to formal definitions and equations" (Hammer \& Elby, 2003. p. 84). Kanim (2001) also obtained similar findings addressing another epistemological barrier between conceptual thinking and formal reasoning. With the explicit links between developed concepts and quantitative problems, these links are termed "bridging exercises" (Kanim, 2001.p. 1). He observed development in students' formal reasoning with an increase in the number of solved quantitative physics problems.

The theoretical framework of Hammer (1994) regarding epistemological beliefs in physics characterizes students' beliefs in three dimensions, such as beliefs about the structure of physics knowledge (isolated pieces vs. coherent), beliefs about the content of physics knowledge (formulas vs. concepts), and beliefs about learning physics (receiving information vs. construction of understanding). With the third dimension of this framework, students' physics learning is classified as "a process of remembering or storing what one has been taught" (Hammer, 1994. p. 159) if it is from an authority and as a "process of applying and modifying one's own judgment" (Hammer, 1994. p. 159) if it involves recreation of ideas independently (naïve constructivism). Hammer and Elby (2002) explain students' epistemologies as "resources" that they held and used. These resources are for understanding, (1) the nature and sources of knowledge, (2) epistemological activities, (3) epistemological forms, and (4) epistemological stances. As a result, student epistemology can be categorized as both public and personal epistemologies. While public epistemology concerns a student's "ideas about the nature of knowledge and learning for society as a whole," personal epistemology is about a student's "ideas about her own knowledge and learning” (Lising \& Elby, 2005. p. 373).

Another issue related to students' epistemologies is contextsensitiveness (Hammer \& Elby, 2002, 2003; Lising \& Elby, 2005). Researchers have explained that it is critical to consider context-sensitivity in the research designs about students' epistemologies because students may present varying epistemologies due to different contexts. According to the resources framework, epistemological resources are fine-grained and comparable to the phenomenological primitives (p-prims) of diSessa (1993). Similar to p-prims, they are activated appropriately and inappropriately due to context (Hammer \& Elby, 2003). For example, resources for understanding the source of knowledge stated in Hammer and Elby's $(2002,2003)$ resources framework may be as "knowledge as propagated stuff" which is "knowledge as a kind of stuff that can be passed from a source to a recipient;" "knowledge as free creation" which is knowledge "invention is a common experience;" and "knowledge as fabricated stuff" which is "knowledge as inferred or developed from other knowledge" (Hammer \& Elby, 2003. p. 56).

Context is a social or cultural environment in which the student is situated. It is central to student learning as an integral part of the learning process (Finkelstein, 2001; Whitelegg and Parry, 1999). It is hypothesized that familiar contexts may help the activation of resources (Hammer \& Elby, 2003). Hence, from the resources perspective, the activation of different sources appropriately in different contexts may be more productive for physics learning rather than considering students having incorrect ideas about knowledge. For this reason, instruction has an important role in helping students identify and activate their epistemological resources for productive learning of physics (Hammer \& Elby, 2003).

Examination of students' epistemology is important because it may affect students' knowledge and learning (Hammer, 1994; 
Hammer \& Elby, 2003; Lising \& Elby, 2005). In addition to the academic background (including the content of the courses that student teachers took during their teacher education programs according to their departments), or sources of knowledge, some other factors such as gender were considered to be important in students' physics knowledge. Girls' lower academic performance in physics compared to boys' was reported to be a considerable research topic to be investigated (Murphy \& Whitelegg, 2006; Stewart, 1998; Zohar \& Sela, 2003). However, some other studies have asserted that gender difference might be due to the result of content and context of the subject to be taught. As a result, attempts to create a more gender-inclusive physics learning content and contexts were intended. From this point of view, we focused on student teachers' physics knowledge with everyday explanations and reasoning, and their epistemological resources accompanying their knowledge to explain everyday phenomena. Both with quantitative measures (e.g., inferential statistics comparing gender, department, source of knowledge vs. physics scores) and a qualitative manner (e.g., descriptive statistics and content analysis of the explanations), we seek answers to the following research questions:

1. How do student teachers explain everyday phenomena in different science contexts?

a. How do student teachers' explanations vary due to gender?

b. How do student teachers' explanations vary due to department?

2. What are the sources of student teachers' physics knowledge reflecting their epistemologies?

a. What is the impact of gender and source of knowledge on student teachers' physics knowledge?

b. What is the impact of department and source of knowledge on student teachers' physics knowledge?

3. How are the everyday conceptions and physical reasoning constructing physics knowledge related?

\section{METHODOLOGY}

We examined physics knowledge together with sources of the knowledge of student teachers who will teach primary and elementary level science in elementary schools (students aged 10-14), in eight different daily-life contexts. A test with eight questions, each of them corresponding to a different context, were developed and implemented for student teachers.

\section{Data Collection}

\section{Contexts for everyday physics phenomena}

When encountering a problem with an everyday phenomenon, we may develop our own idea to handle it or sometimes copy others' knowledge or fix the problem trying different ways related to experience. These approaches are determined by our personal epistemologies and they may vary with context.

Everyday life is full of physical contexts, with problems in such contexts able to be fixed in scientific ways. To examine how student teachers' approach problems in everyday contexts, we determined eight contexts corresponding to particular physical phenomena. In the selection of contexts, we considered that each context (1) is familiar to student teachers in their everyday life, (2) is physically explained, and (3) corresponds to a physics topic in the curricula. Among the significant amount of everyday contexts, we also considered both student teachers' giving answers to questions in a plausible time period. For these reasons, we limited them into eight contexts corresponding to optics and waves, thermodynamics, force and motion, pressure, and nature of matter topics. These were: (1) opening a jar (OJ), (2) keeping honey $(\mathrm{KH}),(3)$ stirring when cooking $(\mathrm{SWC})$, (4) selecting shoe in snow (SSS), (5) drying clothes (DC), (6) selecting dish for microwave cooking (SDMC), (7) redressing the balance in a decelerated car (RBDC), and (8) selecting window blind (SWB).

Handling the problem from each everyday context sometimes required only one physical explanation, for example, "heat conduction" for the selection of a spoon to SWC and "air pressure, expansion, and force" for explaining how to open a tightly sealed cap of a jar (OJ).

\section{Development of concept test}

In the test, in which each question corresponded to an everyday context, we essentially aimed to obtain information about: (1) explanations to everyday physics phenomena, (2) physical explanations of everyday phenomena requiring the use of physics concepts to state reasoning, and (3) sources of their answer and reasoning. In this manner, we could examine student teachers' physics knowledge, epistemologies, context dependency of epistemologies, and how their epistemology allows linkage between their physics conceptions and everyday phenomena. Furthermore, some demographic information required for the research questions (such as gender and department types) were included in the test. After the test questions were constructed, the draft version of the test was examined and evaluated by two experts from the field for face and content validity. After feedback from the experts about questions, the last version of the test presented in Appendix Table 1 was obtained.

\section{Participants of the study and implementation of the test}

By convenience sampling of two universities in Turkey, data in the present study were obtained by implementation of the test to 360 student teachers who will teach elementary science (201 students) and primary science (159) after graduation. In addition, 293 students were female ( $81.6 \%$ ) and 66 students were male (18.4\%) from all years from 1 to 4 in their corresponding program. These student teachers were placed in their programs as a result of Turkey's national university selection and placement exam. The teacher candidates completed the concept test individually in approximately $30 \mathrm{~min}$.

In addition to several professional courses (e.g., classroom management, and educational psychology), subject-matter courses (e.g., physics, chemistry, and biology), and courses that integrate subject knowledge and professional knowledge 
(e.g., methods of teaching, instructional technology, and material development), both programs included physics and physics teaching related courses in their curricula. However, their emphasis on physics is somewhat different such that those in elementary science take more physics courses (e.g., optics, and modern physics) than those student teachers who will teach primary science.

\section{Data Analysis}

Since the test included open-ended questions, data analysis started first with the development of scoring and coding lists. After examination of data by both of the authors carefully, scoring and coding lists were constructed for each question. One of the sample scoring and coding list is presented in Appendix Table 2. The coding is given in Appendix Table 2 allowed to the results in Table 1 and Figure 1 with the analysis of everyday explanation and physics reasoning; Table 2 with the analysis of used physics concepts; and, Tables 3 and 4 with the analysis of sources of knowledge. That is, different kinds of scoring were considered by the researchers due to the research aims. This was also because of consideration of the false positive (correct answer with incorrect reasoning) or false negative (incorrect answer with correct reasoning) nature of given answers, first started by Hestenes et al. (1992). In traditional scoring of the questions, that is, 1 point for the correct answer and 0 point for the wrong answer may not guarantee the presence of correct scientific conceptions all the time. It might be a correct answer with incorrect reasoning. Similarly, a wrong answer may not be as problematic as it is thought. It might be wrong answer with correct reasoning. From the point of view of Hestenes et al.'s (1992), false

Table 1: Percentages of answer and reasoning types for each question

\begin{tabular}{|c|c|c|c|c|c|c|c|c|}
\hline \multirow[t]{3}{*}{ Question } & \multirow{3}{*}{$\begin{array}{l}\text { Answer } \\
\text { (Everyday exp.) }\end{array}$} & \multicolumn{7}{|c|}{ Physical explanation (reasoning) } \\
\hline & & \multicolumn{3}{|c|}{ Conceptual explanation } & \multicolumn{4}{|c|}{ Non-conceptual } \\
\hline & & $\begin{array}{c}\text { Correct } \\
\text { conceptual } \\
\text { explanation }\end{array}$ & $\begin{array}{c}\text { Wrong } \\
\text { conceptual } \\
\text { explanation }\end{array}$ & $\begin{array}{c}\text { Concept } \\
\text { without } \\
\text { explanation }\end{array}$ & $\begin{array}{l}\text { Correct } \\
\text { explanation with } \\
\text { daily life wording }\end{array}$ & $\begin{array}{c}\text { Wrong } \\
\text { non-conceptual } \\
\text { explanation }\end{array}$ & No answer & Total \\
\hline \multirow[t]{4}{*}{$\% \mathrm{OJ}$} & Correct & 16.1 & 26.1 & 12.5 & 6.4 & 26.9 & & 88.1 \\
\hline & Incorrect & 0 & 0.3 & 0.6 & 0 & 2.5 & & 3.3 \\
\hline & No answer & & & & & & 8.6 & 8.6 \\
\hline & Total & 16.1 & 26.4 & 13.1 & 6.4 & 29.4 & 8.6 & 100 \\
\hline \multirow[t]{4}{*}{$\% \mathrm{KH}$} & Correct & 7.8 & 2.8 & 0 & 12.5 & 45.6 & & 70.3 \\
\hline & Incorrect & 0.3 & 0 & 0 & 0.3 & 13.9 & & 14.4 \\
\hline & No answer & & & & & & 15.3 & 15.3 \\
\hline & Total & 8.1 & 2.8 & 0 & 12.8 & 59.4 & 15.3 & 100 \\
\hline \multirow[t]{4}{*}{$\% \mathrm{SWC}$} & Correct & 43.3 & 11.1 & 6.7 & 2.2 & 20.8 & & 84.2 \\
\hline & Incorrect & 0.3 & 0.3 & 0.3 & 0 & 5.3 & & 6.1 \\
\hline & No answer & & & & & & 9.7 & 9.7 \\
\hline & Total & 43.6 & 11.4 & 6.9 & 2.2 & 26.1 & 9.7 & 100 \\
\hline \multirow[t]{4}{*}{$\% \mathrm{SSS}$} & Correct & 31.7 & 11.1 & 6.1 & 24.2 & 5.0 & & 78.1 \\
\hline & Incorrect & 0.8 & 1.1 & 0.3 & 1.4 & 6.9 & & 10.611 .4 \\
\hline & No answer & & & & & & 11.4 & \\
\hline & Total & 32.5 & 12.2 & 6.4 & 25.6 & 11.9 & 11.4 & 100 \\
\hline \multirow[t]{4}{*}{$\% \mathrm{DC}$} & Correct & 33.6 & 3.9 & 8.9 & 29.7 & 10.3 & & 86.4 \\
\hline & Incorrect & 0 & 0 & 0.3 & 0 & 1.1 & & 1.4 \\
\hline & No answer & & & & & & 12.2 & 12.2 \\
\hline & Total & 33.6 & 3.9 & 9.2 & 29.7 & 11.4 & 12.2 & 100 \\
\hline \multirow[t]{4}{*}{$\%$ SDMC } & Correct & 4.7 & 32.2 & 1.1 & 1.7 & 22.2 & & 61.9 \\
\hline & Incorrect & 0 & 3.6 & 0 & 0.8 & 11.7 & & 16.1 \\
\hline & No answer & & & & & & 21.9 & 21.9 \\
\hline & Total & 4.7 & 35.8 & 1.1 & 2.5 & 33.9 & 21.9 & 100 \\
\hline \multirow[t]{4}{*}{$\%$ RBDC } & Correct & 14.4 & 4.7 & 13.3 & 29.2 & 13.3 & & 75.0 \\
\hline & Incorrect & 0.6 & 0.8 & 1.4 & 1.7 & 0.8 & & 5.3 \\
\hline & No answer & & & & & & 19.7 & 19.7 \\
\hline & Total & 15.0 & 5.6 & 14.7 & 30.8 & 14.2 & 19.7 & 100 \\
\hline \multirow[t]{4}{*}{$\%$ SWB } & Correct & 46.1 & 7.5 & 3.3 & 12.5 & 19.2 & & 88.6 \\
\hline & Incorrect & 1.4 & 0.8 & 0.6 & 0.8 & 2.5 & & 6.1 \\
\hline & No answer & & & & & & 5.3 & 5.3 \\
\hline & Total & 47.5 & 8.3 & 3.9 & 13.3 & 21.7 & 5.3 & 100 \\
\hline
\end{tabular}

OJ: Opening a jar, KH: Keeping honey, SWC: Stirring when cooking, SSS: Selecting shoe in snow, DC: Drying clothes, SDMC: Selecting dish for microwave cooking, RBDC: Redressing the balance in a decelerated car, SWB: Selecting window blind 


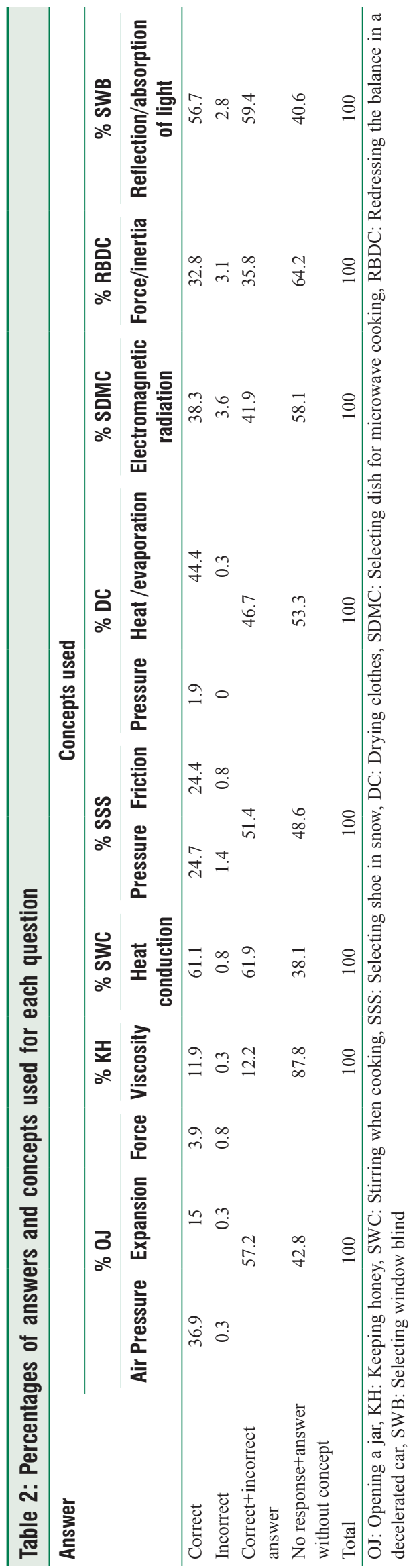

positive and false negative nature of the questions, we scored answers and reasoning, not as 1 and 0 points as usual, but gave partial credits for certain cases. Since in the reasoning tier, we intentionally wanted the responders to use physics concepts in their explanations with the phrase "please state your reasoning with physics concepts" we gave more points to a conceptual explanation with an appropriate physical concept even though it was not totally correct than a correct explanation without any physical concepts (or say daily life wording).

In addition to giving partial credit for the answer and reasoning due to our aim, scores for each question were calculated by the sum of a subject's score for his/her answer and reasoning of the corresponding question. For an individual question in the test, one's score ranged from 0 to 10 ; while for the total test, it ranges from 0 to 80 . In addition to scoring for answer and reasoning, for each question, other coding schemes were used for the source of knowledge for reasoning and for the physics concept(s) used in the answer and reasoning. Furthermore, we consulted the opinions of the two experts in physics and physics education majors to validate the scores we assign in Appendix Table 2.

Scoring and coding were performed by two independent raters. Similarities and differences between the scoring and coding of the two independent raters were discussed until a consensus was reached. After converting all qualitative data into a quantitative form, we performed statistical tests (independent-samples t-test for research question one, twoway between-group ANOVA for research question two, and Pearson product-moment correlation for research question three) using the Statistical Package for the Social Sciences version 22 program.

\section{RESULTS}

\section{Student Teachers' Physics Knowledge}

The analysis started first by an examination of the descriptive statistics for the total test scores. Out of 80 , the mean of student teachers' test scores was 45.8 with a standard deviation of 11.8. The Cronbach's alpha coefficient $(\alpha)$ was calculated as a measure of the internal consistency of the test scores and was found to be 0.62 , which explains that at least $62 \%$ of the total score variance is due to the true score variance (Crocker and Algina, 1986).

After some descriptive analysis (e.g. mean, standard deviation), we performed some inferential statistics (e.g. independentsamples t-test) analysis for examining whether there was a difference between student teachers' everyday physics explanations according to their gender and department. The resulting $\rho$ value of independent-samples t-test analysis indicates whether or not statistically significant differences exist. The threshold for significance for our analysis was set at $\rho \leq 0.05$. That means a $95 \%$ certainty that our data do not represent a random result, but a true difference. An independent-samples t-test was conducted to compare total test scores for females and males. According to the results, 


\begin{tabular}{|c|c|c|c|c|c|c|c|c|}
\hline Sources & $\%$ OJ & $\% \mathrm{KH}$ & \%SWC & $\%$ SSS & $\% \mathrm{DC}$ & $\%$ SDMC & \% RBDC & $\%$ SWB \\
\hline No answer & 2.2 & 5.5 & 2.8 & 5.5 & 4.6 & 9.4 & 6.9 & 6.9 \\
\hline Experience, observation & 29.9 & 30.9 & 29.7 & 36.8 & 31.4 & 22.6 & 57.3 & 28.9 \\
\hline Course, teacher, textbook & 4.2 & 4.1 & 5.9 & 17.0 & 6.9 & 8.5 & 12.7 & 18.9 \\
\hline Media & 1.4 & 1.2 & 2.3 & 3.4 & 0.6 & 6.5 & 0 & 0.3 \\
\hline Other sources (intuitive, reflex, guess etc.) & 2.0 & 2.3 & 2.0 & 4.6 & 2.6 & 2.4 & 8.4 & 4.3 \\
\hline Mother & 48.6 & 41.1 & 52.0 & 6.0 & 45.2 & 40.3 & 2.3 & 33.2 \\
\hline Father & 2.8 & 3.2 & 0 & 9.2 & 0.3 & 0 & 4.6 & 0 \\
\hline Friend & 2.0 & 0.9 & 0.6 & 0.3 & 0.3 & 0.6 & 0.9 & 0.3 \\
\hline Other family & 7.0 & 10.8 & 4.8 & 17.2 & 8.1 & 9.7 & 6.9 & 7.2 \\
\hline Total & 100.0 & 100.0 & 100.0 & 100.0 & 100.0 & 100.0 & 100.0 & 100.0 \\
\hline
\end{tabular}

OJ: Opening a jar, KH: Keeping honey, SWC: Stirring when cooking, SSS: Selecting shoe in snow, DC: Drying clothes, SDMC: Selecting dish for microwave cooking, RBDC: Redressing the balance in a decelerated car, SWB: Selecting window blind

Table 4: Mean of each question for sources of knowledge

\begin{tabular}{|c|c|c|c|c|c|c|c|c|}
\hline \multirow[t]{2}{*}{ Sources } & 0J & KH & SWC & SSS & DC & SDMC & RBDC & SWB \\
\hline & Mean & Mean & Mean & Mean & Mean & Mean & Mean & Mean \\
\hline No answer & 2.500 & 2.158 & 5.100 & 3.895 & 3.563 & 0.438 & 3.500 & 4.833 \\
\hline Experience, observation & 6.075 & 3.981 & 7.133 & 5.742 & 6.156 & 4.078 & 5.714 & 6.960 \\
\hline Course, teacher, textbook & 7.467 & 6.786 & 7.952 & 8.000 & 7.583 & 6.276 & 5.477 & 7.742 \\
\hline Media & 7.600 & 5.500 & 6.625 & 5.167 & 5.000 & 5.000 & - & 6.000 \\
\hline Other sources (intuitive, reflex, guess, etc.) & 4.000 & 4.500 & 5.000 & 5.625 & 6.556 & 5.000 & 5.034 & 7.733 \\
\hline Mother & 5.868 & 3.894 & 6.766 & 6.810 & 6.841 & 4.964 & 4.625 & 7.112 \\
\hline Father & 5.200 & 4.000 & - & 6.875 & 5.000 & - & 6.000 & - \\
\hline Friend & 6.714 & 4.000 & 4.000 & 10.000 & 0.000 & 6.500 & 5.667 & 1.000 \\
\hline Other family & 5.920 & 3.432 & 6.765 & 5.083 & 6.137 & 5.030 & 4.708 & 7.600 \\
\hline
\end{tabular}

OJ: Opening a jar, KH: Keeping honey, SWC: Stirring when cooking, SSS: Selecting shoe in snow, DC: Drying clothes, SDMC: Selecting dish for microwave cooking, RBDC: Redressing the balance in a decelerated car, SWB: Selecting window blind

there was a significant difference in total scores for females $(\mathrm{M}=47.21, \mathrm{SD}=11.02)$ and males $(\mathrm{M}=39.53, \mathrm{SD}=13.43$; $\mathrm{t}[85.8]=4.33, \rho=0.00)$. The magnitude of the differences in the means was moderate (eta squared $=0.0498$ ) in terms of effect size. When the same analysis was performed for each question separately, except two of the questions in the test (DC and RBDC), significant mean differences between male and female scores in favor of females were found. That means for the overall test and for six questions in the test, females outperformed males significantly.

An independent-samples t-test was performed also to compare total test scores for student teachers from the two different departments having a different number of physics courses in the program to train primary and elementary science teachers. A statistically significant difference in total scores was found for the student teachers for primary science teaching $(M=40.2$, $\mathrm{SD}=11.71)$ and student teachers for elementary science teaching $(\mathrm{M}=50.2, \mathrm{SD}=9.94 ; \mathrm{t}[310]=-8,64, \rho=0.00)$. The magnitude of the differences in the means was large (eta squared $=0.17$ ) in terms of effect size. That means student teachers at elementary science teaching program outperformed the student teachers at primary science teaching program significantly.

To gain an in-depth insight into student teachers' answers (everyday explanations), concept use and reasoning (physical explanations) in their answers for individual questions in the test were then determined by performing some further investigations. In Table 1, the percentages of answer and reasoning types for each question in the test are provided.

In the table, the first three reasoning types are conceptual, while the last three are non-conceptual, where it can be seen that even when student teachers gave correct answers, their reasoning may be non-conceptual in nature. In all questions in the test, student teachers presented more correct answers than their incorrect or blank answers. In addition, in most of the questions (SWC, SSS, DC, and SWB) student teachers gave correct answers with correct conceptual explanations. In contrast to these correct conceptual explanations, in two of the questions ( $\mathrm{OJ}$ and $\mathrm{KH})$, however, student teachers mostly gave correct answers with incorrect explanations which were wrong and non-conceptual. In addition to totally correct and conceptual explanations and wrong and non-conceptual explanations, student teachers mostly stated wrong conceptual explanations, which correspond to the use of physical concepts incorrectly for selecting a dish for the microwave (SDMC). The last type of explanation was observed mostly in RBDC, which is a correct explanation with daily life wording. In this category, although student teachers explained the inertia, they used non-physical terminologies from everyday life. 
The contexts explained in a conceptually correct manner (SWC, SSS, DC, and SWB) are those that student teachers frequently engaged with in their daily life. However, student teachers mostly provided conceptually wrong explanations for microwave use (SDMC). This result may be because a microwave is not frequently used as an ordinary oven. For this reason, student teachers' explanations indicate that they considered the working principle of an ordinary oven (it works by heating), and they incorrectly explained the physical phenomena considered in microwave (it works by vibrating the molecules using electromagnetic waves). This finding points out the context-sensitivity of the explanations stated by Hammer and Elby $(2002,2003)$. When the non-conceptual explanations were examined, KH was explained both incorrectly and non-conceptually. This result may be because of limited content in physics curricula stressing the viscosity. The context of RBDC was explained correctly, but daily life wording maybe because of students' limited connection of inertia with daily life. Table 2 presents the answers of subjects categorized according to the concepts used in their reasoning for each question. In addition, Table 2 also indicates the total percentages of the reasoning with appropriate (correct) and inappropriate (incorrect) use of the concepts as well as the percentages of no responses and the answers without concept use.

As it is presented in Table 2, in their answer to SWC, most participants used a related concept (heat conduction) in their answer $(61.9 \%)$; while in their answer to $\mathrm{KH}$, they used the viscosity concept the least (12.2\%). In their answer to three of the questions (OJ, SSS, and DC), they used more than one concept. In most of the contexts, almost half of the student teachers used the concepts correctly. For example, for SWC, "What kind of spoon do you use when you are cooking?" was asked, it was first expected from the student teachers "wooden or silicon spoon" as an answer of the question and reasoning about the transfer of heat by conduction in the determination of total score for each question. However, at this step, student teachers' explanations about their reasoning were examined in terms of "heat conduction." This is because students may give explanations either conceptual by considering physics or nonconceptual explanations without physics. As a result parallel with the physics explanations, at this step student teachers displayed what physics concepts they used when they were explaining the reasons for their answers. It is noticeable that when they used a related concept in a great proportion in all of the contexts, they mostly gave correct answers to the question (Table 1).

Reinterpreting this table by considering the findings in Table 1, the findings are coherent. For example, while SWC is explained in a mostly conceptually correct manner in Tables 1 and 2, a physical concept "heat conduction" was stated by most of the student teachers for selecting spoon for stirring when cooking (SWC). Similarly, in Table 1, KH was explained mostly wrong and in a non-conceptual manner; in addition, it has the largest percentage use of incorrect explanations (13.9\%). In Table 2, it is observed that most student teachers did not answer this question with a physical concept - viscosity - (87.8\%) and the level of those who did use it correctly was rather low $(11.9 \%)$. To summarize, the limited use of physical concepts may explain the non-conceptual and incorrect explanations.

\section{Sources of Knowledge and Context Dependency of Sources}

To investigate student teachers' source of physics knowledge in each question, we asked how they had received this information. Regardless of the context, among 2880 instances (360 teacher candidates $\times 8$ contexts), Figure 1 presents the context independent sources.

As shown in Figure 1, student teachers reflected 34\% of their physics knowledge based on the information gained by their "mother." In addition, other sources such as "father," "friend," "other family members," and "media" correspond to a total of 14\%. From Hammer and Elby's $(2002,2003)$ resources framework that the theoretical approach is based on, this result corresponds to the "knowledge as propagated stuff" in which knowledge of other people is a kind of "stuff" that can be passed to student teachers from different sources. Student teachers' explanations based on their "experience" are $33 \%$, and this percentage is comparable to the information which comes from their "mother." This result can be explained with "knowledge as free creation" which student teachers invented their knowledge by their experience with the context. At this point, knowledge as propagated stuff like "mother told me" and knowledge as creation like "I saw/experienced my mother did" were discriminated because the second one contains any kind of experience that may be personal experience by doing something and experiencing somebody is doing something. According to Figure 1, 10\% of student teachers' physics knowledge is based on the "course" where they learned physics. This percentage is low in comparison to other dominant sources such as "mother" and "experience." Again with the same framework, this kind of knowledge corresponds to "knowledge as-fabricated stuff" in which student teachers' knowledge about the context is inferred

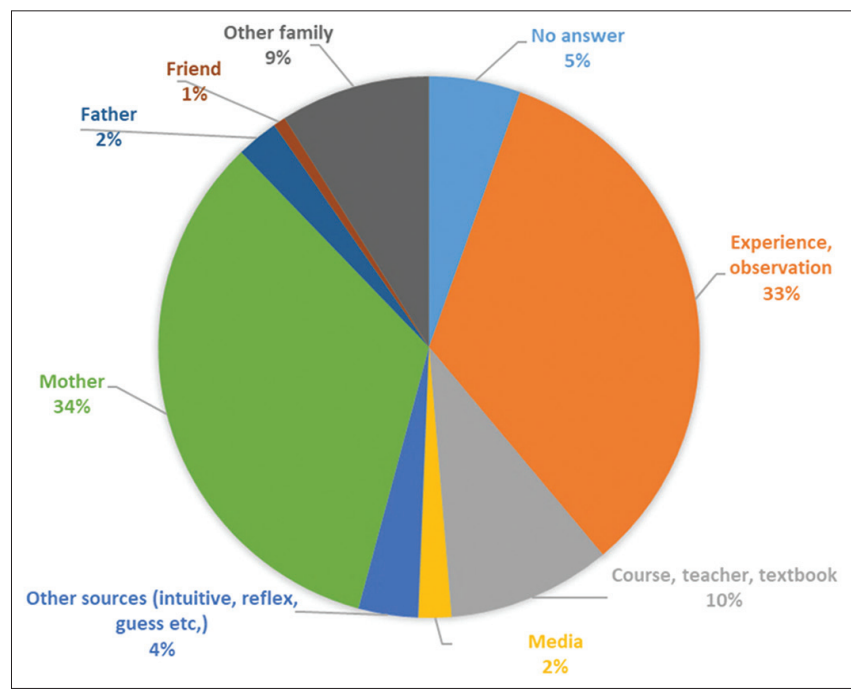

Figure 1: Student teachers' sources of everyday explanations 
or developed from other knowledge such as textbooks or teachers in the course. Differing from the framework of Hammer and Elby (2002), student teachers also reflected 4\% of their physics knowledge based on "intuition, reflex, guess, etc.” In 5\% of student teachers' knowledge, sources were not stated. To summarize, by considering context-independent explanations, almost half of the student teachers (48\%) displayed their knowledge as "propagated stuff" from one source to another to explain everyday phenomena in this study. To examine the variation in the sources due to the contexts, Table 3 represents the percentages of sources of physics knowledge for each question corresponding to each context.

As presented in Table 3, in most of the questions (in contexts OJ, KH, SWC, DC, SDMC, and SWB) in the test, "mother" was stated mostly as the source of their knowledge that is propagated from a source. In two of the questions (SSS and RBDC), "experience and observation" that is knowledge as free creation.

Referring to Table 1, it can be reconsidered that while "mother" was mostly stated as the source in the contexts of SWC, DC, and SWB which allowed correct and conceptual explanations, in the contexts of $\mathrm{OJ}$ and $\mathrm{KH}$, it allowed mostly wrong and non-conceptual, and in SDMC it allowed wrong conceptual explanations. However, the interesting context is OJ.Although it is widely used, it led to student teachers providing mostly wrong and non-conceptual explanations. This context contains three physical concepts (air pressure, expansion, and force), which may have partly influenced the explanations.

As mentioned previously, in a single question in the test, the maximum possible score that can be obtained was 10 . In Table 4, the mean of each question in comparison to the corresponding source of knowledge is given for each question separately. In this way, we can gather information about the mean for each stated source knowledge in the questions.

Table 4 indicates that student teachers could explain the contexts based on epistemologically different knowledge, such as fabricated, propagated, or invented knowledge. However, the scores obtained from each question correspond to a context, and different sources may contribute to the scores differently. For example, in most of the questions (in contexts $\mathrm{KH}, \mathrm{SWC}, \mathrm{DC}$, and SWB), the means were the highest for the student teachers who stated that their knowledge comes from a "course" fabricated with other knowledge such as teachers or textbooks. In two of the questions (in contexts SSS and $\mathrm{SDMC}$ ), the means were the highest for "friend" as stated as a source of knowledge that is propagated from a source. Similarly, for the OJ question, the highest mean was obtained for "media" as a source, while for the RBDC question, it was "father" corresponding to propagated knowledge.

When Tables 3 and 4 are compared, it can be observed that incompatibility of most stated percentages for a source of knowledge and maximum scores belong to different kinds of sources. This result also indicates that a dominant source of knowledge for each context allows individuals to understand everyday physics phenomena; however, that source may not provide completely scientific information or that the knowledgebased on that source may not be correctly constructed by individuals. For example, the media as a source of OJ corresponds to $1.4 \%$ (Table 3 ), which is the least-stated source in this context. However, the maximum score in this question corresponds to media source (7.6, in Table 4). On the other hand, in the KH context, most student teachers stated "mother" as the source of their knowledge ( $41.1 \%$, in Table 3$)$. However, scores in this question reflect that one of the minimum scores corresponds to this source (3.9, in Table 4). Another example is for the knowledge based on experience, which is invented knowledge. For the SSS context, although knowledge from experience is dominant (36.8\%, in Table 3), a score explained with experience is lower than some of the other sources (5.7, in Table 4). This result may also indicate a potential limitation of refinement of everyday phenomena during experience.

To summarize the findings in Table 4 by considering Table 1 findings, although student teachers indicated "mother" as the source of their knowledge, obtained knowledge in the course, which is fabricated in physics classes, allowed the highest scores in three of four contexts (SWC, DC, and SWB). In addition, this result may explain the higher percentage of correct and conceptual explanations in these contexts in Table 1. Similarly, in the contexts mostly explained incorrectly and non-conceptually in Table 1, propagated knowledge from media (in OJ) and fabricated knowledge in the course (in $\mathrm{KH}$ ) explained the highest scores although most of the students stated "mother" as a source of their knowledge. In two of the contexts, although "experience" was stated as the source of knowledge, propagated knowledge from a friend (in SSS: Correct and conceptual explanation in Table 1) and from the father (in RBDC: Correct explanation with daily life wording in Table 1) indicated the highest scores. Finally, in an SDMC context, although student teachers indicated "mother" as the source of knowledge, the highest score was observed by another source "friend" that the knowledge propagated from.

In addition to the qualitative interpretation of sources of physics knowledge, a two-way between-groups ANOVA was conducted to explore the impact of source and gender on student teachers' total scores from the test, as well as to explore the impact of source and department on student teachers' total scores from the test. First of all, for each student teacher, the most stated source "mode" of knowledge for all eight-question in the test was determined (subjects who stated a) sources selected less than by two subjects and b) equal number of sources "multimode" selected are omitted from the analysis for the sake of analysis). Two-way ANOVA allowed us to test simultaneously for the effect of each of our independent variables (source and gender) on the dependent variable (total test score) and also identifies any interaction effect. An interaction effect occurs when the effect of one independent variable on the dependent variable depends on the level of a second independent variable. In comparison of the total test scores according to source and gender, a statistically significant main effect for gender $(F[1,298]=5.098, \rho=0.025)$ was observed; however, the effect 
size was small (partial eta squared $=0.017)$. The main effect for source $(\mathrm{F}[4,298]=1.815, \rho=0.126)$ and the interaction effect $(F[4,298]=0.339, \rho=0.851)$ did not reach statistical significance. The non-significant interaction effect indicates that there is no significant difference in the effect of source of knowledge on total test scores for males and females. The significant main effect for gender means that males and females differ in terms of their total test scores, but practically this difference is small because of small effect size.

In comparison of the total test scores according to source and department, a statistically significant main effect for department $(F[1,299]=5.355, \rho=0.021)$ with small effect size (partial eta squared $=0.018)$ and interaction effect $(\mathrm{F}[4$, $299]=3.505, \rho=0.008$ ) with moderate effect size (partial eta squared $=0.045)$ was noted. The main effect for source $(F[4$, $299]=1.310, \rho=0.266)$ did not reach statistical significance. These results can be interpreted as although the source of knowledge indicates significant differences by interacting with gender and department, it does not statistically differ for the total scores. These findings also confirm the contribution of each source in terms of physics knowledge and individuals selecting their own ways differently in different contexts to gain overall physics knowledge.

\section{Linkage of Everyday Explanations with Physics Conceptions}

For the third research question, the manner in which student teachers linked everyday explanations with physics conceptions was examined. The relationship between total answer scores (corresponding to everyday explanations) and total reasoning scores (corresponding to reasoning) for student teachers was investigated using a Pearson product-moment correlation coefficient. There was a medium, positive correlation between the two variables $(r=0.380, \rho<0.005)$. This finding indicates that student teachers could have linked physics concepts with everyday phenomena moderately.

\section{DISCUSSION, CONCLUSIONS, AND IMPLICATIONS}

There can be considered two-way causality between physics learning and beliefs; while beliefs may be affected by students' experience of success and failure, they may also affect what students learn (Hammer, 1994). In this study, we examined student teachers' physics knowledge with their everyday explanations and physical reasoning pertaining to everyday concepts. In addition, how sources of knowledge influenced student teachers' physics learning were also investigated.

Females' lower academic performance, attitudes, and experience in physics compared to males have taken a higher level of attention of researchers, and many efforts have been made to reduce this gender gap. Some studies have proposed that gender differences depend merely on the content and context of a subject. In the question of contexts of the present research; however, a statistically significant mean difference between females' and males' academic performance was found, and which favored the females. This result may stem from the contexts of the questions in the test, which may have been more appealing or familiar to females than males. Hammer and Elby (2003) explained that resources constituting the naïve epistemologies may be activated in familiar contexts appropriately.

Context sensitivity of the explanations was also observed in some of the contexts independent of gender. For example, it was observed that student teachers mostly provided conceptually wrong explanations for microwave because microwave use is not as common as an ordinary oven in Turkey. This finding pointing out the context-sensitivity of the explanations stated by Hammer and Elby $(2002,2003)$ may also explain the influence of cultural contexts on physics explanations.

According to the comparison for the departments, the statistically significant difference found may be due to the difference in the number of courses taken in these two programs. As the number of courses are taken related to physics learning or teaching increases, the student teachers' total score of answer and reasoning subsequently also increases.

In $34 \%$ of instances, the student teachers indicated "mother" as a source of their physics explanations that corresponds to "knowledge as a propagated stuff" due to Hammer and Elby's $(2002,2003)$ framework. As similar, they stated "experience" as a source of their explanations corresponds to "knowledge as a free creation" in $33 \%$ of the instances. However, the mean of each question in comparison to the corresponding source of knowledge indicated that the source may not provide completely scientific information. In other words, the knowledge based on that source may not be correctly constructed by individuals. In conclusion, according to this dimension of the framework of explaining physics learning, "propagated" and "fabricated" knowledge allowed the highest scores in each context despite the different kinds of sources stated by student teachers. In addition, in contrast to statistical difference in total scores due to gender and department, the main effect for source did not reach statistical significance when exploring the impact of "source and gender" and "source and department" on student teachers" total scores. This indicates the contribution of each source construction of physics knowledge. Individuals select their own ways differently - either by fabrication, or propagation, or invention of knowledge - in different contexts to gain overall physics knowledge.

As students learn about the world formally through school education or informally through their experiences, they tend to explain everyday phenomena with physics concepts. In our study, the results about student teachers' reasoning and use of physics concepts indicated that correctly use of physics concepts to explain phenomena facilitated correct reasoning; however, limited use resulted in wrong explanations. However, their explanations and reasoning regarding everyday phenomena may or may not be scientifically compatible with expert opinions. Even complex problem-solving or advanced courses taken do not necessarily lead to scientific understanding (Kaltakci-Gurel et al., 2016).

Teachers often subscribe to the same difficulties as their 
students (Abell, 2007). Student teachers, even after completing successfully their courses in their programs, have certain difficulties about concepts that may sometimes be activated in particular contexts. Therefore, improving the preparation of teachers so that they are well qualified to teach physics is a crucial aim of educators.

As Einstein noted, science is a refinement of everyday thinking, and hence a physicist can proceed by analyzing the nature of everyday thinking (Hammer \& Elby, 2003). Although student teachers could relate concepts in all of the questions and mostly gave correct answers to the questions, moderate correlation between everyday explanations and reasoning indicates that student teachers could link physics with everyday life only in a rather limited manner. This result is similar to the findings of Lising and Elby (2005) and Kanim's (2001) indicating an epistemological barrier between formal and everyday reasoning and conceptual thinking and formal reasoning, respectively. Students may have difficulty in bridging these different types of physics knowledge. Physics educators should have insights into the nature of students' knowledge and reasoning (Hammer \& Elby, 2003). They should design their physics courses by considering students' epistemologies to remove the hidden barrier between everyday and formal concepts because traditional physics courses may not change students' epistemologies (Ding, 2014). Physics instructors that practice in interpretation of physical formalism and relating it to the real world are necessary for students to successfully grasp physics concepts (McDermott, 1993).

\section{REFERENCES}

Abell, S.K. (2007). Research on science teacher knowledge. In: Abell, S.K., \& Lederman, N.G. (Eds.), Handbook of Research on Science Education. New Jersey: Lawrance Erlbaum Associates Inc. p1105-1149.

Beichner, R.J. (1994). Testing student interpretation of kinematics graphs. American Journal of Physics, 62(8), 750-762.

Chi, M.T.H., Feltovich, P.J., \& Glaser, R. (1981). Categorization and representation of physics problems by experts and novices. Cognitive Science, 5, 121-152.

Crocker, L., \& Algina, J. (1986). Introduction to Classical and Modern Test Theory. Philadelphia, PA: Holt, Rinehart and Winston, Inc.

Didiş, N., Eryılmaz, A., \& Erkoç, Ş. (2014). Investigating students' mental models about the quantization of light, energy and angular momentum. Physical Review Special Topics: Physics Education Research, 10(2), 020127.

Ding, L. (2014). Verification of causal influences of reasoning skills and epistemology on physics conceptual learning. Physical Review Special Topics: Physics Education Research, 10, 1-5.

diSessa, A.A. (1993). Towards an epistemology of physics. Cognition and Instruction, 10(2-3), 105-225.

Engelhardt, P.V., \& Beichner, R.J. (2004). Students' understanding of direct current resistive electric circuits. American Journal of Physics, 72(1), 98-115.

Finkelstein, N.D. (2001). Context in the Context of Physics and Learning. Rochester, New York: Paper Presented at the Physics Education Research Conference, July 25-26, 2001.

Halloun, I., \& Hestenes, D. (1985a). The initial knowledge state of college physics students. American Journal of Physics, 53(11), 1043-1048.

Halloun, I., \& Hestenes, D. (1985b). Common sense concepts about motion. American Journal of Physics, 53(11), 1056-1065.

Hammer, D., \& Elby, A. (2002). On the form of a personal epistemology.
In: Hofer, B.K., \& Pintrich, P.R. (Eds.), Personal Epistemology: The Psychology of Beliefs about Knowledge and Knowing. Mahwah, NJ: Lawrence Erlbaum Associates Publishers. p169-190.

Hammer, D., \& Elby, A. (2003). Tapping epistemological resources for learning physics. The Journal of the Learning Sciences, 12(1), 53-90.

Hammer, D.M. (1994). Epistemological beliefs in introductory physics. Cognition and Instruction, 12(2), 151-183.

Hestenes, D., \& Wells, M. (1992). A mechanics baseline test. The Physics Teacher, 30, 159-166.

Hestenes, D., Wells, M., \& Swackhamer, G. (1992). Force concept inventory. The Physics Teacher, 30, 141-158.

Itza-Ortiz, S.F., Rebello, S., \& Zollman, D. (2004). Students' models of Newton's second law in mechanics and electromagnetism. European Journal of Physics, 25, 81-89.

Ivanjek, L., Shaffer, P.S., McDermott, L.C., Planinic, M., \& Veza, D. (2015). Research as a guide for curriculum development: An example from introductory spectroscopy. Identifying student difficulties with atomic emission spectra. American Journal of Physics, 83(1), 85-90.

Kaltakci-Gurel, D., Eryilmaz, A., \& McDermott, L.C. (2016). Identifying pre-service physics teachers' misconceptions and conceptual difficulties about geometrical optics. European Journal of Physics, 37(4), 1-30.

Kaltakci-Gurel, D., Eryilmaz, A., \& McDermott, L.C. (2017). Development and application of a four-tier test to assess pre-service physics teachers' misconceptions about geometrical optics. Research in Science and Technological Education, 35(2), 238-260.

Kanim, S.E. (2001). Connecting Concepts to Problem-Solving. Rochester, New York: Paper Presented at Physics Education Research Conference, July 25-16. Available from: http://www.per-central.org/items/detail. cfm?ID $=4320$ \&Relations $=1$. [Last accessed on 2019 Sep 25].

Lewis, E.L., \& Linn, M.C. (1994). Heat energy and temperature concepts of adolescents, adults, and experts: Implications for curricular improvements. Journal of Research in Science Teaching, 31, 657-677.

Lising, L., \& Elby, A. (2005). The impact of epistemology on learning: A case study from introductory physics. American Journal of Physics, 73(4), 372-382.

McDermott, L.C. (1993). How we teach and how students learn-a mismatch? American Journal of Physics, 61(4), 295-298.

Murphy, P., \& Whitelegg, E. (2006). Girls and physics: Continuing barriers to "belonging". The Curriculum Journal, 17(3), 281-305.

Peşman, H., \& Eryılmaz, A. (2010). Development of a three-tier test to assess misconceptions about simple electric circuits. The Journal of Educational Research, 103, 208-222.

Reif, F. (1995). Millikan lecture 1994: Understanding and teaching important scientific thought processes. American Journal of Physics, 63(1), 17-32.

Reif, F. (1997). How can we help students acquire effectively usable physics knowledge? In: Redish, E.F., \& Rigden, J.S. (Eds.), International Conference on Undergraduate Physics Education: The Changing Role of Physics Departments in Modern Universities. Woodbury, New York: American Institute of Physics. p179-195.

Songer, N.B., \& Linn, M.C. (1991). How do students' views of science influence knowledge integration? Journal of Research in Science Teaching, 28(9), 761-784.

Stewart, M. (1998). Gender issues in physics education. Educational Research, 40(3), 283-293.

Thornton, R.K., \& Sokoloff, D.R. (1998). Assessing student learning of Newton's Laws: The force and motion conceptual evaluation and the evaluation of active learning laboratory and lecture curricula. American Journal of Physics, 66(4), 338-352.

Vokos, S., Shaffer, P.S., Ambrose, B.S., \& McDermott, L.C. (2000). Student understanding of the wave nature of matter: Diffraction and interference of particles. American Journal of Physics, 68(7), 42-51.

Whitelegg, E., \& Parry, M. (1999). Real-life contexts for learning physics: Meanings, issues and practice. Physics Education, 34(2), 68-72.

Wittmann, M.C., Steinberg, R.N., \& Redish, E.F. (1999). Making sense of how students make sense of mechanical waves. The Physics Teacher, $37(1), 15-21$.

Zohar, A., \& Sela, D. (2003). Her physics, his physics: Gender issues in Israeli advanced placement physics classes. International Journal of Science Education, 25(2), 245-268. 


\section{APPENDIX}

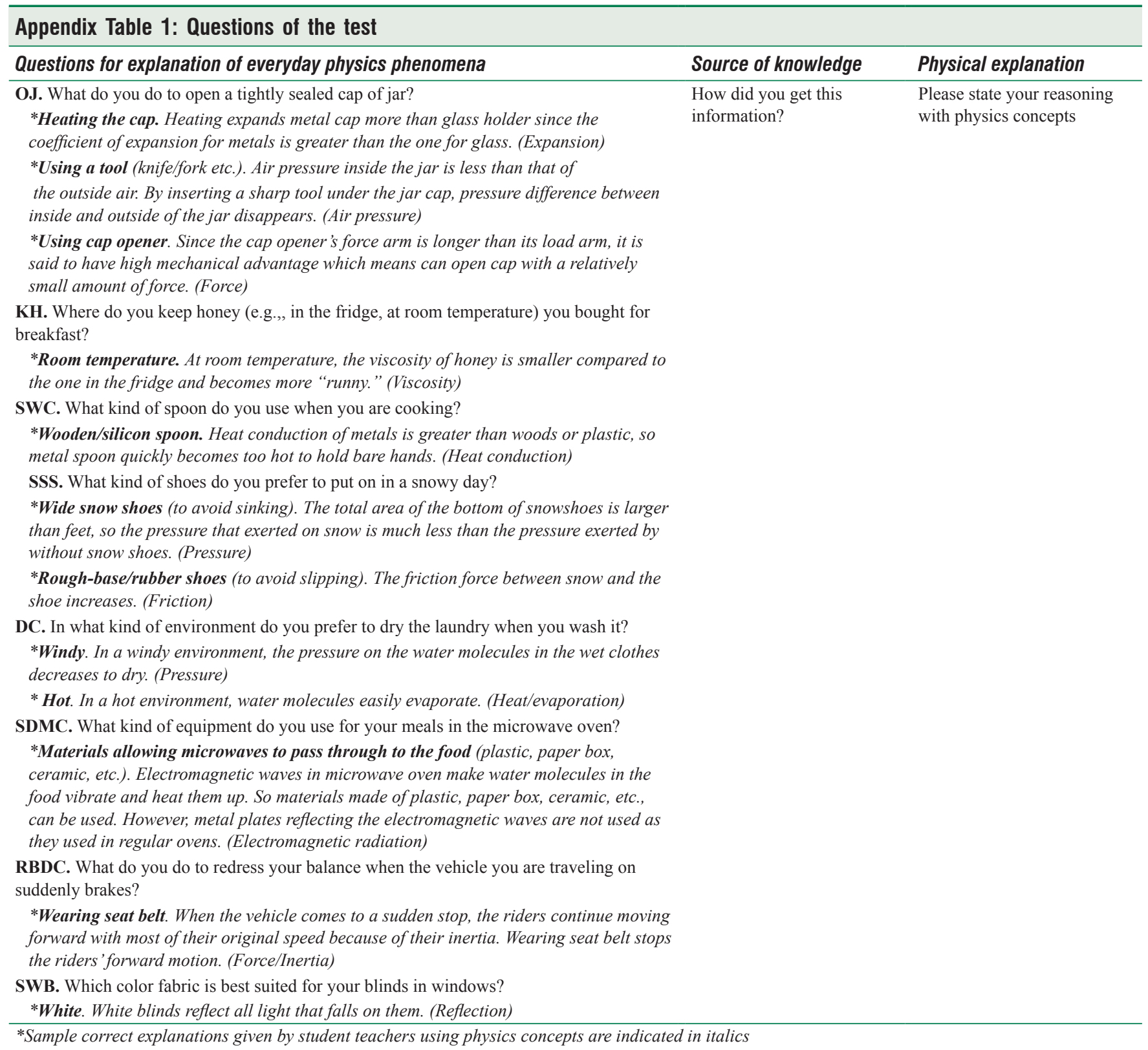




\begin{tabular}{|c|c|c|c|}
\hline \multicolumn{4}{|c|}{ Appendix Table 2: A sample scoring and coding for opening a jar question } \\
\hline \multicolumn{3}{|c|}{ Scoring the test: sample scoring for opening a jar } & \multirow{2}{*}{$\begin{array}{c}\text { Point } \\
4\end{array}$} \\
\hline Answer (Everyday ex & Ination) & Correct answer & \\
\hline \multirow{2}{*}{\multicolumn{2}{|c|}{ (For Table 1) }} & Incorrect/implausible answer & 0 \\
\hline & & No idea/no answer & - \\
\hline \multirow{3}{*}{$\begin{array}{l}\text { Physics explanation } \\
\text { (Reasoning) }\end{array}$} & Conceptual & Correct conceptual explanation (e.g., Jar cap expands then the jar is open) & 6 \\
\hline & & Wrong conceptual explanation (e.g., Pressure decreases inside the jar) & 3 \\
\hline & & Concept without explanation (e.g., Pressure) & 2 \\
\hline \multirow[t]{3}{*}{ (For Table 1) } & Non-conceptual & Correct explanation with daily life wording (e.g., Jar cap enlarges then the cap is open) & 1 \\
\hline & & Wrong non-conceptual explanation (e.g., Taking air inside) & 0 \\
\hline & & No answer/ No information & - \\
\hline \multicolumn{3}{|c|}{ Categorical coding: sample coding for correctly answered opening a jar } & Code \\
\hline \multirow{3}{*}{\multicolumn{2}{|c|}{$\begin{array}{l}\text { Concept Used in Reasoning } \\
\text { (For Table 2) }\end{array}$}} & Air Pressure (e.g., By the help of a tool (knife/fork etc.) letting the air inside the jar) & 1 \\
\hline & & Expansion (e.g., By putting the jar cap in hot water OR By heating the jar cap) & 2 \\
\hline & & Force (e.g., By the help of simple machines (a cap opener etc.) & 3 \\
\hline \multirow{10}{*}{\multicolumn{2}{|c|}{$\begin{array}{l}\text { Source of Knowledge /Reasoning } \\
\text { (For Table } 3 \text { and 4) }\end{array}$}} & No answer/ No information & 0 \\
\hline & & Experience/Observation & 1 \\
\hline & & Course/Teacher/Textbook & 2 \\
\hline & & Media (TV/Internet/ General books) & 3 \\
\hline & & Another person & \\
\hline & & Mother & 4.1 \\
\hline & & Father & 4.2 \\
\hline & & Friend & 4.3 \\
\hline & & Others & 4.4 \\
\hline & & Others (General knowledge, intuition, reflex, guess etc.) & 5 \\
\hline
\end{tabular}

